\title{
Response of the Distal Tubule and Cortical Collecting Duct to Vasopressin in the Rat
}

\author{
Philip B. Woodhall and C. Craig Tisher \\ From the Division of Nephrology, Department of Medicine and Department of \\ Pathology, Duke University Medical Center, Durham, North Carolina 27710
}

\begin{abstract}
A в S T R A C T Renal micropuncture observations in the rat suggest that the entire "distal tubule" (defined by the micropuncturist as that portion of the renal tubule extending between the macula densa and its first junction with another (renal tubule) may be responsive to vasopressin. However, this portion of the renal tubule contains two segments that are morphologically dissimilar. The "early" distal tubule is lined by epithelium characteristic of the distal convoluted tubule, while the "late" distal tubule is lined by epithelium characteristic of the cortical collecting duct. Thus, the present study was initiated to identify the most proximal site of action of vasopressin in the distal renal tubule. A water diuresis was established in rats with hereditary hypothalamic diabetes insipidus. In one-half of the animals the diuresis was interupted by an i.v. infusion of exogenous vasopressin. Morphological preservation of the kidneys was initiated after induction of vasopressin-induced antidiuresis or during maximum water diuresis. Cell swelling and dilatation of intercellular spaces, morphological findings indicative of vasopressin responsiveness, were observed in the cortical collecting duct including the late segment of the distal tubule, a segment that has also been described by morphologists as the initial collecting tubule. Mòphological evidence of vasopressin-responsiveness was not observed in the early distal tubule (distal convoluted tubule). Additional morphological studies in Wistar, Long-Evans, and Sprague-Dawley rats demonstrated a marked difference in the random availability of distal convoluted tubules versus initial collecting tubules potentially available for micropuncture just beneath the renal capsule. The results suggest that hypotonic tubular fluid entering the early distal tubule (distal convoluted tubule) remains hypotonic to plasma until it enters the
\end{abstract}

Dr. Tisher is the recipient of Research Career Development Award HE 440074 from the U. S. Public Health Service.

Received for publication 30 May 1973 and in revised form 3 August 1973

The Journal of Clinical Investigation Volume 52 December 1973·3095-3108 late distal tubule (initial collecting tubule) and that vasopressin-induced osmotic equilibration is a function of the latter segment alone. The findings emphasize the importance of morphological characterization of those segments of the renal tubule that are subjected to physiological investigation.

\section{INTRODUCTION}

The distal tubule of the rat kidney, as defined by the morphologist, is composed of three segments that are histologically distinct. These include the ascending thick limb of Henle (pars recta), the macula densa (pars maculata), and the distal convoluted tubule (pars convoluta) $(1,2)$. The remaining portion of the renal tubule, the collecting duct, is lined by epithelium morphologically distinct from that lining the convoluted portion of the distal tubule $(1,2)$. The first portion of the cortical collecting duct has been variously termed the connecting portion (2) or the initial collecting tubule (3). The latter term will be used in this paper. In most mammalian kidneys the transition from the distal convoluted tubule to the cortical collecting duct (i.e., the initial collecting tubule) occurs well before the first junction of one renal tubule with another; thus, the first junction of two renal tubules is formed by two so-called initial collecting tubules.

Despite the fact that the convoluted segment of the distal tubule (as defined morphologically) ends well before its first junction with another tubule, it has been common practice at the micropuncture table to define the "distal tubule" or "distal convolution" as that segment of the renal tubule that extends between the macula densa and the site of the first junction with another distal tubule or distal convolution (4-7). When defined in this manner, it can be seen that this segment of the renal tubule is structurally heterogeneous in character. Thus, the "early" distal tubule of the renal micropuncturist is lined by epithelium characteristic of the distal 
convoluted tubule (pars convoluta), whereas the "late" distal tubule is lined by epithelium characteristic of the intial collecting tubule.

The present investigation was initiated to determine whether the structural heterogeneity of the so-called distal tubule (as defined at the micropuncture table) was associated with morphological evidence of functional heterogeneity in response to the administration of exogenous vasopressin. Previous morphological studies have demonstrated that certain segments of the collecting duct of the mammalian kidney are responsive to vasopressin. In the presence of a favorable osmotic gradient, that is, from the lumen to the interstitium, vasopressininduced bulk water flow across the tubular epithelium is associated with cell swelling and dilatation of the lateral and basilar intercellular spaces. These morphological changes have been observed in vivo in the medullary col lecting duct of the rat (8) and in vitro in isolated segments of the rabbit cortical tubule (9). Thus, these same morphological features were employed in the present study as a morphological marker to determine the most proximal site of action of vasopressin in the renal tubule of the rat. The results of this investigation revealed that the entire cortical collecting duct (beginning with the iniial collecting tubule) was responsive to vasopressin. On the other hand, no evidence was found to suggest that the distal convoluted tubule, as defined morphologically, was responsive to vasopressin.

\section{METHODS}

Selected morphological features of the distal convoluted tubule and the cortical collecting duct were documented in 13 animals with hereditary hypothalamic diabetes insipidus $(\mathrm{DI})^{1}$ (10) during water diuresis, vasopressin-induced antidiuresis without hydropenia, or after vasopressin administration after the antecedent institution of water deprivation. Additional observations on the morphology of the dista convoluted tubule and cortical collecting duct were recorded during antidiuresis in 7 Wistar rats and 34 Sprague-Dawley rats.

In the initial phases of the investigation, 11 adult DI rats weighing 183-257 $\mathrm{g}$ were studied after an overnight fast during which free access to water was permitted. On the morning of the experimental day, water diuresis was initiated by the administration of two separate water loads via gastric gavage at 30 -min intervals (each water load was equivalent to $3 \%$ of the body weight). Immediately thereafter the rats were anesthetized via the intraperitoneal administration of sodium pentobarbital $(35 \mathrm{mg} / \mathrm{kg}$ body weight), tracheostomy was performed, and polyethylene catheters were inserted into a carotid artery and one jugular vein. Water diuresis was sustained by the constant i.v. infusion of a hypotonic sodium chloride solution (110 $\mathrm{mM} \mathrm{Na} \mathrm{Cl} ; 25 \mathrm{mM} \mathrm{Na} \mathrm{HCO}_{3} ;$ osmolality $=260$ mosmol $/$ $\mathrm{kg} \mathrm{H}_{2} \mathrm{O}$ ) at $0.2 \mathrm{ml} / \mathrm{min}$. The mean arterial blood pressure was monitored constantly with a P23D pressure transducer connected to a Sanborn recorder (Hewlett-Packard Co. Waltham Div., Waltham, Mass.). The abdomen was then

${ }^{1}$ Abbreviation used in this paper: DI, diabetes insipidus. opened and the left kidney was isolated and prepared for micropuncture as described previously (11). The temperature of the exposed kidney was maintained by a constant surface drip of warmed $\left(37^{\circ} \mathrm{C}\right)$ isotonic saline. Timed collections of urine were obtained from each separate kidney via the placement of polyethylene catheters in the left ureter (P.E. 50) and the bladder (P.E. 60). Urine osmolality was measured cryoscopically with an Advanced Instruments osmometer (Advanced Instruments, Inc., Needham Heights, Mass.). Experimental manipulation and/or morphological observations were initiated when a sustained water diuresis, equivalent to at least $35 \mu \mathrm{l} / \mathrm{min} / \mathrm{kidney}$, had been established. In five animals renal morphological examination was carried out during water diuresis. In six other DI rats renal tissue was fixed and prepared for morphological examination between 6 and $60 \mathrm{~min}$ after the rapid conversion of water diuresis to antidiuresis via the institution of a constant i.v. infusion of aqueous vasopressin (Pitressin, Parke, Davis \& Co., Detroit, Mich.) at a rate of $0.15 \mathrm{mU} / \mathrm{min}$.

Two additional DI rats weighing 206 and $163 \mathrm{~g}$, respectively, were studied during vasopressin administration after the institution of varying degrees of water deprivation. Both of these animals were starved overnight and then prepared surgically as described above. One animal was allowed free access to water before study but additional fluid was not administered after the induction of anesthesia (except for an infusion of isotonic saline at 0.02 $\mathrm{ml} / \mathrm{min}$ for $40 \mathrm{~min}$ during surgical preparation to replace estimated surgical blood loss). The second animal was deprived of water for $9 \mathrm{~h}$ before surgery but i.v. fluids were not given either during or after surgical preparation After surgical preparation was completed, both animals received an i.v. infusion of vasopressin $(0.15 \mathrm{mU} / \mathrm{min})$ for $10 \mathrm{~min}$. Fixation of renal tissue was then initiated in preparation for morphological examination.

Morphological observations on that segment of the renal tubule between the macula densa and the first junction with another renal tubule were made in 7 Wistar rats and 34 Sprague-Dawley rats. All animals were studied during normally spontaneous antidiuresis, and surgical preparation was carried out in a manner identical to that outlined above for DI rats.

Morphological studies in DI rats. Renal tissue was preserved for morphological investigation by dripping either $2 \% \mathrm{OsO}_{4}$ buffered in potassium phosphate (osmolality $\left.225 \mathrm{mosmol} / \mathrm{kg} \mathrm{H}_{2} \mathrm{O} ; \mathrm{pH} 7.4-7.6\right)$ or a mixture of glutaraldehyde and formaldehyde (12) diluted to half-strength and buffered in potassium phosphate (osmolality: 960 mosmol/ $\mathrm{kg} \mathrm{H}_{2} \mathrm{O}$; $\mathrm{pH}$ 7.4-7.6) over the surface of the undisturbed left kidney for $30 \mathrm{~min}$. Thereupon the kidney was excised quickly and the well-preserved outer cortex was removed and divided into several blocks approximately $1 \mathrm{~mm}^{3}$ in size. Aldehyde-preserved tissue was fixed for an additional $4 \mathrm{~h}$ at room temperature in the same fixative solution; it was then rinsed overnight in a potassium phosphate buffer with added sucrose and postfixed for $1 \mathrm{~h}$ in $2 \% \mathrm{OsO}_{4}$. Tissue initially fixed in $\mathrm{OsO}_{4}$ was fixed for 1 additional $h$ in $\mathrm{OsO}_{4}$ and then rinsed briefly in the potassium phosphate buffer. All tissues were dehydrated in a graded series of alcohols and embedded in Epon epoxy resin (Epon Adhesive Synthetic Resin, Shell Chemical Co., New York (13).

Tissue sections for light microscopy were cut $1 \mu \mathrm{m}$ in thickness from the Epon-embedded material and stained with toluidine blue (14). Sections for electron microscopy were cut with diamond knives, doubly stained with uranyl 
acetate (15) and lead citrate (16), and examined and photographed with an AEI 6B electron microscope (AEI Scientific Apparatus Inc., Elmsford, N. Y.).

The morphology of the distal convoluted tubule and the cortical segment of the collecting duct in the diuretic and antidiuretic DI animals was first evaluated qualitatively by both light and electron microscopy. The material was then subjected to quantitative morphometric techniques in an attempt to document the presence or absence of vasopressininduced transcellular or intercellular osmotic water flow or both in the two segments of the renal tubule under investigation. Since transcellular water flow causes an increase in cell volume that should be reflected by an increase in cell height, the height of individual cells lining the cortical segment of the collecting duct and the distal convoluted tubule was measured. By planimetric techniques, the total cross-sectional area of the epithelium lining the cortical segments of the collecting duct was also determined as another indication of cell volume change in the two physiological conditions. These measurements included the area occupied by the intercellular space and intracellular vacuoles, since the two compartments could not be distinguished at the light microscopic level. For these measurements distal convoluted tubules and cortical collecting ducts appearing in the cross-section in the $1-\mu \mathrm{m}$ tissue sections were photographed with a Zeiss Photomicroscope II (Carl Zeiss, Inc., New York) at an initial magnification of 160, with Kodak Panatomic Photographic Film (Eastman Kodak Co., Rochester, N. Y.). All prints were enlarged by a factor of 12 (final magnification: $1,920 \times)$. To insure proper orientation, only those sections with identifiable renal capsule were used. In addition to the light microscopic measurements of cell height in distal convoluted tubules, electron micrographs were also taken of the distal convoluted tubules of DI rats in water diuresis and vasopressin-induced antidiuresis to compare the width of the lateral intercellular spaces in the two physiological

TABLE I

Urine Flow Rate and Urine Osmolality in DI Rats before Tissue Preservation

\begin{tabular}{|c|c|c|c|}
\hline Study group & $\begin{array}{c}\text { Animal } \\
\text { no. }\end{array}$ & Urine flow & Urine osmolality \\
\hline & & $\mu l / \min /$ kidney & $\mathrm{mosmol} / \mathrm{kg} \mathrm{H} \mathrm{H}_{2} \mathrm{O}$ \\
\hline \multirow{6}{*}{ Water diuresis } & 008 & 74 & 153 \\
\hline & 200 & 91 & 241 \\
\hline & 190 & 63 & 245 \\
\hline & 202 & 69 & 197 \\
\hline & 17 & 69 & 176 \\
\hline & Mean & 73 & $202 \pm 18^{*}$ \\
\hline \multirow[t]{7}{*}{ Antidiuresis } & 009 & $3.2(37.7) \ddagger$ & $530(201) \&$ \\
\hline & 010 & $4.0(52)$ & $357(145)$ \\
\hline & 210 & $28.7(37)$ & $483(227)$ \\
\hline & 2 & $5.0(38)$ & $1,000(165)$ \\
\hline & 58 & $22 \quad(42)$ & $784(132)$ \\
\hline & 129 & $56 \quad(76)$ & $369(102)$ \\
\hline & Mean & 10.2 & $592 \pm 141 * \|$ \\
\hline
\end{tabular}

* SEM.

$\ddagger$ Value in parenthesis indicates maximum urine flow before administration of vasopressin.

$\S$ Value in parenthesis indicates urine osmolality at the time of maximum urine flow.

$\|$ The mean value does not include animals 58 and 129 , fixed $1 \mathrm{~h}$ after administration of vasopressin.

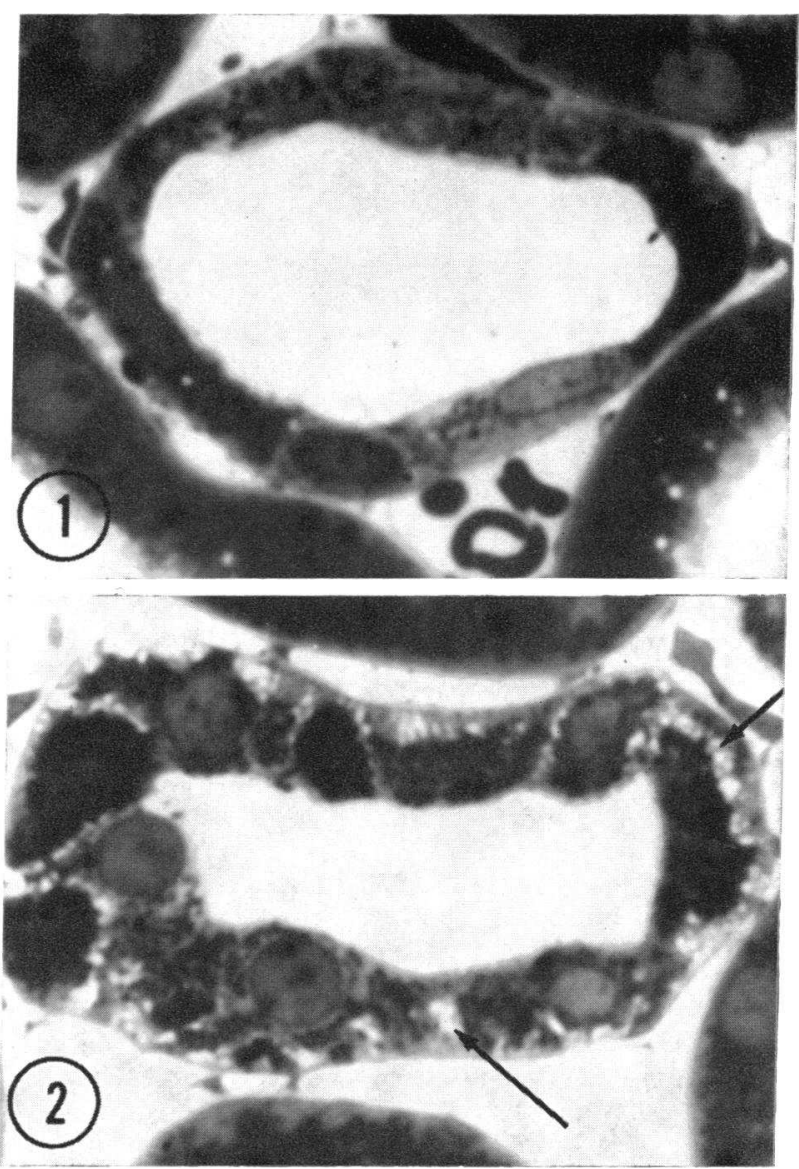

FIgURE 1 Photomicrograph depicting the typical appearance of a cortical collecting duct from an untreated DI rat during water diuresis. Magnification $\times 1,400$.

FIGURE 2 Photomicrograph demonstrating cell swelling and dilatation of lateral and basilar intercellular spaces (arrows) in a cortical collecting duct from DI rat in which the water diuresis was converted to antidiuresis by the administration of exogenous vasopressin. Magnification $\times 1,400$.

conditions. For these measurements three separate tubules were examined in each animal. Six measurements of width were taken randomly from two different cells within each tubule examined. Width of the intercellular spaces was measured with an Optical Comparator, Model P-1523, (Scherr-Tumico, Inc., St. James, Minn.) directly from negatives taken at an original magnification of $5,000 \times$. These measurements were made without prior knowledge of the physiological status of the animal, i.e., water diuresis versus antidiuresis.

Morphological studies in Wistar and Sprague-Dawley rats. These observations were made for two primary purposes: $(a)$ to characterize the type of epithelium that lines those so-called distal tubules (extending from the macula densa to the first junction with another renal tubule) that are potentially accessible to renal micropuncture, and $(b)$ to define the type of epithelium present at the point of junction between two distal tubules. $1-\mu \mathrm{m}$ tissue sections were examined by light microscopy and compared with 

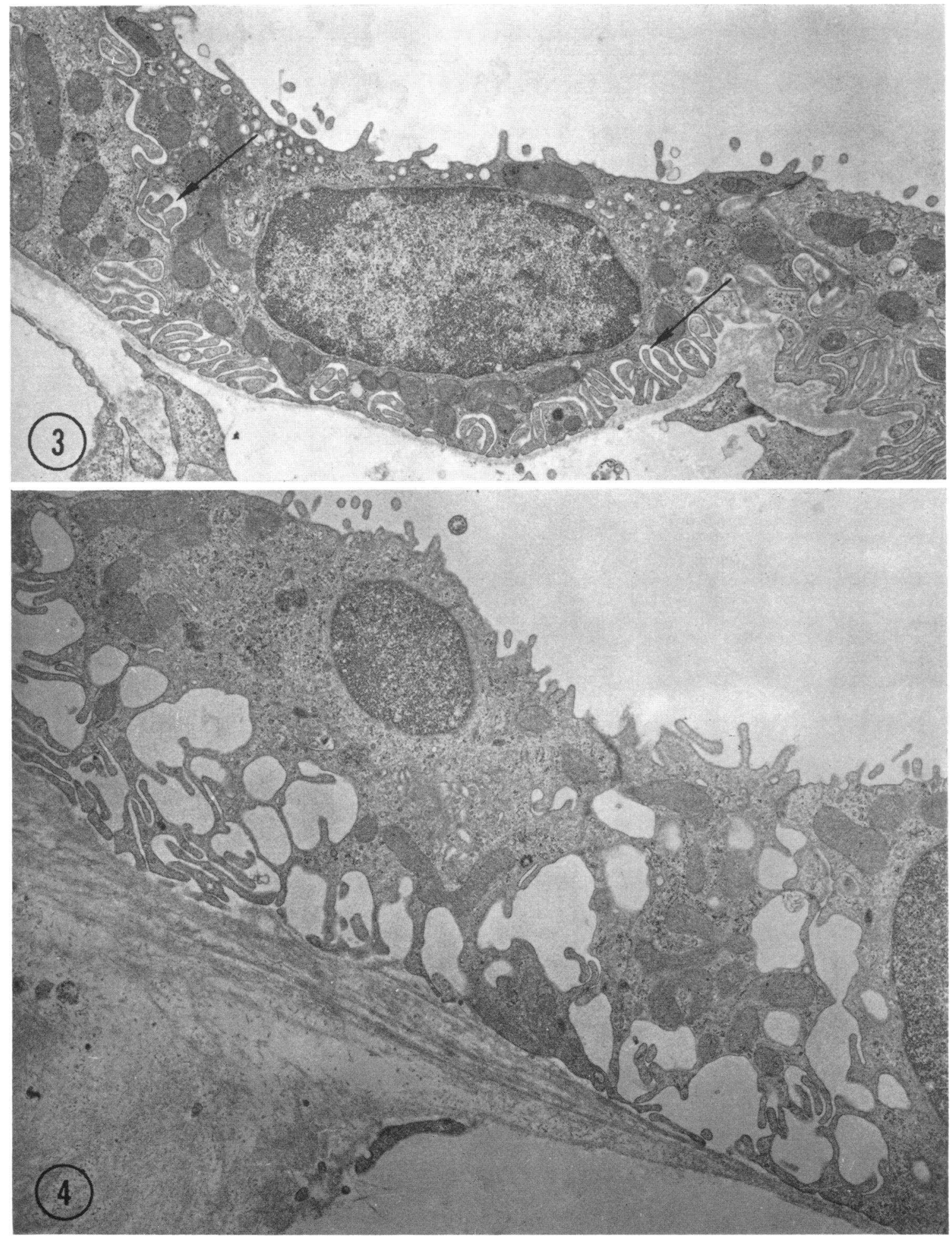

FIGURE 3 Low-magnification electron micrograph depicting a short segment of cortical collecting duct from an untreated DI rat in water diuresis. No enlargement of intercellular spaces (arrows) or evidence of cell swelling is present in either the light or principal cells on the right and left, or the dark or intercalated cell in the center. Magnification $\times 12,000$. 
sections obtained from DI rats. Only those sections that included the renal capsule were used and only those tubules (excluding proximal tubules) that lay directly beneath the capsule and which would normally have been accessible to micropuncture were evaluated. The tubules were classified on the basis of their cellular composition as distal convoluted tubule, transition region, or cortical collecting duct. The transition region was defined as that segment of the renal tubule in which cells resembling both the distal convoluted tubule and the cortical collecting duct could be seen in the same cross-section. In these same animals (as well as in DI rats), serial $1-\mu \mathrm{m}$ tissue sections were also cut to trace the formation of the first junction of one renal tubule with another. Junctional observations were not limited to sections with visible renal capsule; junctions throughout the outer one-third of the cortex were examined.

Numerical data were analyzed by Student's $t$ test. Data are expressed as mean \pm standard deviation unless indicated otherwise and $P$ values less than 0.05 were considered significant.

\section{RESULTS}

Physiological observations (Table $I$ ). The average urine flow at the time of fixation in the five untreated DI rats (water diuresis alone) was $73 \mu \mathrm{l} / \mathrm{min} / \mathrm{kidney}$; the average urine osmolality averaged $202 \pm$ SE 18 mos$\mathrm{mol} / \mathrm{kg} \mathrm{H} \mathrm{H}_{2} \mathrm{O}$. In the six animals in which water diuresis was interrupted by the administration of exogenous vasopressin, the urine osmolality immediately before fixation

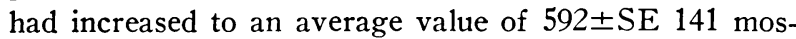
$\mathrm{mol} / \mathrm{kg} \mathrm{H} \mathrm{H}_{2} \mathrm{O}$ and urine flow had fallen to $10.2 \mu \mathrm{l} / \mathrm{min} /$ kidney. An amount of urine sufficient for analysis could not be obtained from the two animals subjected to water deprivation before the administration of exogenous vasopressin. Physiological observations were not obtained in healthy and presumably antidiuretic non-DI rats.

Morphological observations. The general morphological appearance of the collecting duct epithelium and that lining the distal convoluted tubule in DI rats was identical to that described previously in other strains of laboratory rats and it will not be detailed further. The terminal portion of the distal tubule of the micropuncturist was lined by epithelium that was collecting-duct in type, i.e., like that of the initial collecting tubule of the morphologist.

In the five untreated DI rats in which the kidney was fixed in situ during water diuresis, the lumen of the cortical collecting ducts (including the initial collecting tubule) was widely patent. Both the light or principal cells and the dark or intercalated cells were cuboidal in shape and enlargement of the lateral or basilar intercellular spaces was not observed (Fig. 1). In contrast, the appearance of the cortical collecting ducts (including the initial collecting tubules) differed markedly in the six DI rats treated with vasopressin before fixation (Fig. 2). Light microscopic examination revealed that the outer diameter of the collecting ducts, when viewed in cross-section, was somewhat reduced in comparison to that observed in animals undergoing water diuresis; furthermore, the cells lining the tubules were greater in height. These two events led to a reduction in luminal diameter and they suggested that cell swelling had occurred. Most striking, however, was the presence of markedly dilated lateral and basilar intercellular spaces separating the individual cells lining the collecting ducts.

Differences in the morphologic appearance of collecting duct epithelium in the two physiological conditions were even more obvious with electron microscopy. In untreated DI rats undergoing water diuresis, enlargement of the intercellular spaces was not evident and the lateral cell membranes and the interlocking lateral interdigitations of adjacent cells were immediately juxtaposed (Fig. 3 ). On the other hand, the exposure of collecting duct epithelium to vasopressin during maximum water diuresis was accompanied by the appearance of the large lateral and basilar intercellular spaces noted previously with light microscopy (Fig. 4). The majority of the lateral interlocking processes of adjacent cells were no longer in direct apposition to each other. There was marked rarefaction of the cytoplasm of the principal or light cells, suggesting that the cells were swollen and had increased in volume. The most marked enlargement of the intercellular spaces was noted in kidney tissue fixed 6-10 min after the establishment of antidiuresis. The collecting duct epithelium from kidneys fixed at $60 \mathrm{~min}$ continued to exhibit evidence of cellular swelling, but the frequency of lateral intercellular space dilatation was sharply reduced. In many animals the intercellular spaces were dilated most markedly within the initial collecting tubule at a point near its transition with the distal convoluted tubule. Hydropenic animals receiving exogenous vasopressin did not exhibit detectable morphological evidence of cellular swelling or intercellular space dilatation.

In contrast to the above observations on epithelium of the collecting duct, water diuresis and vasopressin-induced antidiuresis were not associated with discernible differences in the morphological appearance of the distal convoluted tubule on light microscopy (Figs. 5 and $6)$. The luminal and outside diameters of the distal convoluted tubules were similar in the two physiological conditions as was the height of individual cells lining the tubules. These findings were confirmed with electron

FIGURE 4 Low-magnification electron micrograph depicting a segment of a cortical collecting duct from a DI rat in which the water diuresis was converted to antidiuresis with exogenous vasopressin. Lateral and basilar intercellular spaces are widely dilated and the light or principal cells on the right and left are swollen. A dark or intercalated cell is present just to the right of center. Magnification $\times 10,000$. 

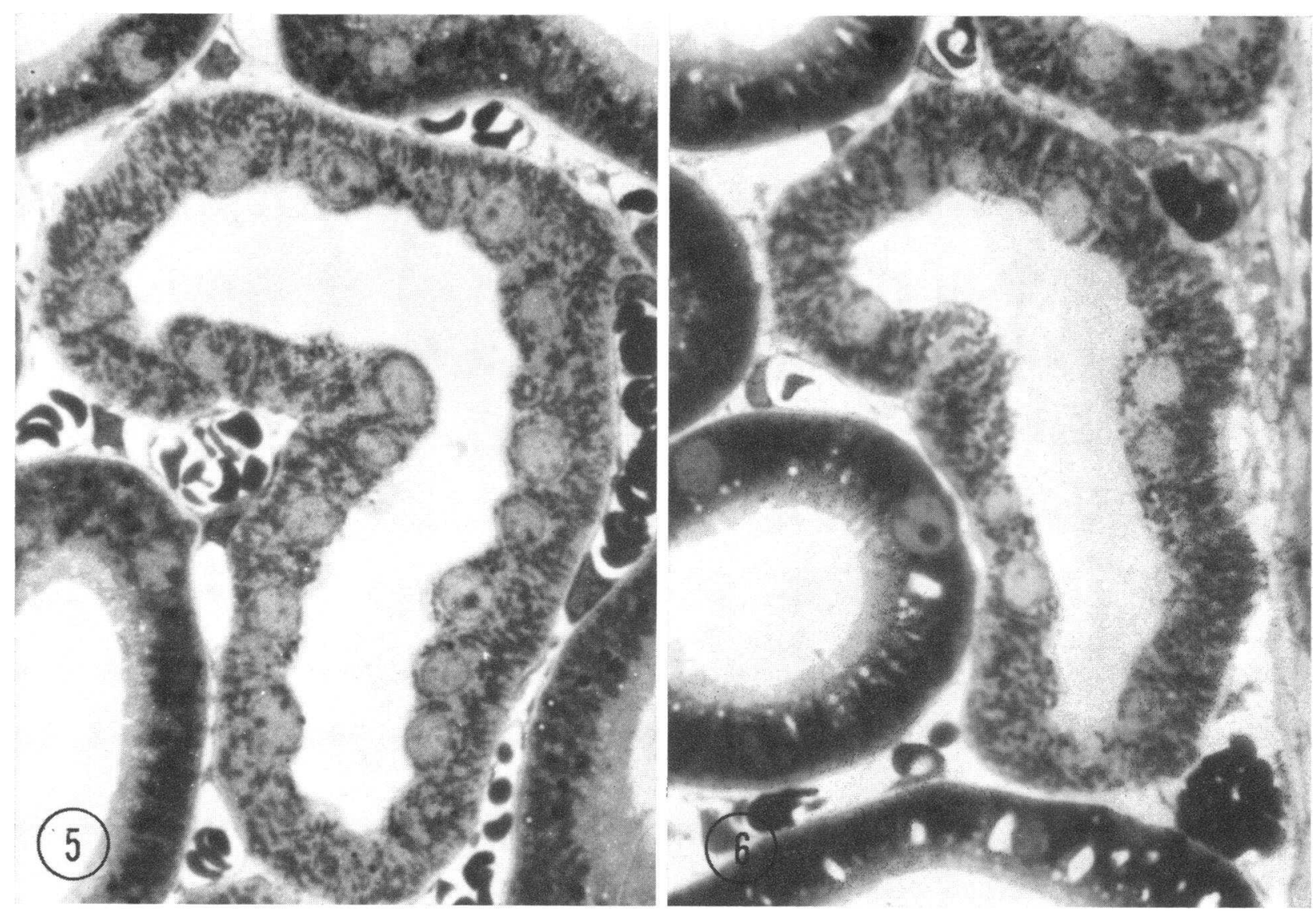

Figlke 5 Photomicrograph of distal convoluted tubule from a DI rat in water diuresis. Magnification $\times 1,050$.

FIGURE 6 Photomicrograph of a distal convoluted tubule from a DI rat converted from water diuresis to antidiuresis by the administration of exogenous vasopressin. Magnification $\times 1,075$.

microscopy (Figs. 7 and 8). Neither cell swelling nor dilatation of the lateral and basilar intercellular spaces was observed in the distal convoluted tubules from vasopressin-treated antidiuretic animals.

The qualitative morphological observations described above were confirmed by semiquantitative morphometric measurements. These measurements were performed on cortical collecting ducts (including the initial collecting tubules) and distal convoluted tubules from 7 of the 13 animals in which tissue fixation was initiated at the height of water diuresis (four rats) or up to 20 min after the beginning of vasopressin-induced antidiuresis (three rats). Aldehyde fixation was used in each of these seven animals. The results of these measurements are depicted in Tables II and III. In the cortical collecting duct, including the initial collecting tubule, the outside diameter of the tubule did not differ significantly in the two groups of animals. However, a significant reduction in luminal diameter was observed in the vasopressin-treated antidiuretic group $(26.1 \pm \mathrm{SD} 5.1 \mu \mathrm{m}$ vs. $22.7 \pm \mathrm{SD} 4.7 \mu \mathrm{m}$, $P<0.01)$. The average height of the light or principal cells in the four untreated animals undergoing water diuresis was $5.7 \pm \mathrm{SD} 1.0 \mu \mathrm{m}(n=71)$ vs. $6.7 \pm \mathrm{SD} 1.3$ $\mu \mathrm{m} \quad(n=71)$ in the three vasopressin-treated animals $(P<0.001)$. The average height of the dark or intercalated cells in the untreated diuretic animals was $5.3 \pm$ $\mathrm{SD} 1.1 \mu \mathrm{m}(n=61)$ vs. $6.8 \pm \mathrm{SD} 1.0 \mu \mathrm{m}(n=59)$ in the treated animals $(P<0.001)$. These results suggest that the cells of the collecting ducts in vasopressintreated animals were swollen, and cellular volume had increased. They confirm the qualitative morphological observations and they are consistent with an increased cellular entry of water through the apical or luminal membrane in the presence of vasopressin and a favorable osmotic gradient. The results of planimetry support such a conclusion as well, despite the fact that statistical significance was not quite achieved; the average cross-sectional area of the epithelium lining the cortical collecting duct of untreated diuretic animals was $601 \pm \mathrm{SD} 150 \mu \mathrm{m}^{2}$ $(n=33)$ vs. $668 \pm \mathrm{SD} \mu \mathrm{m}^{2}(n=33)$ in the animals receiving vasopressin $(P<0.06)$.

The results of the morphometric measurements of 


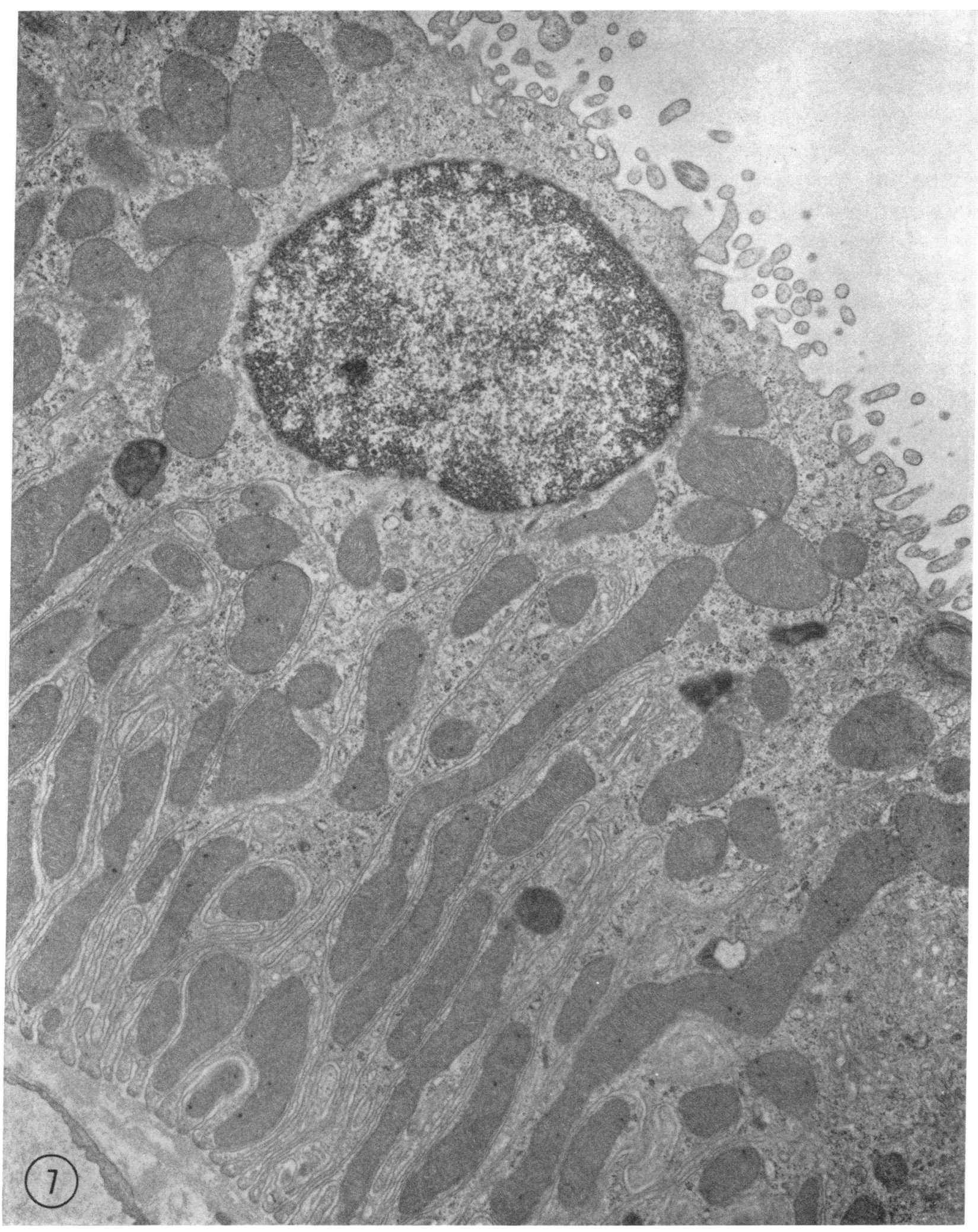

FIGURE 7 Electron micrograph of distal convoluted tubule from a DI rat in water diuresis. The tubule lumen is at the upper right and the basement membrane at the lower left. Magnification $\times 14,500$. 


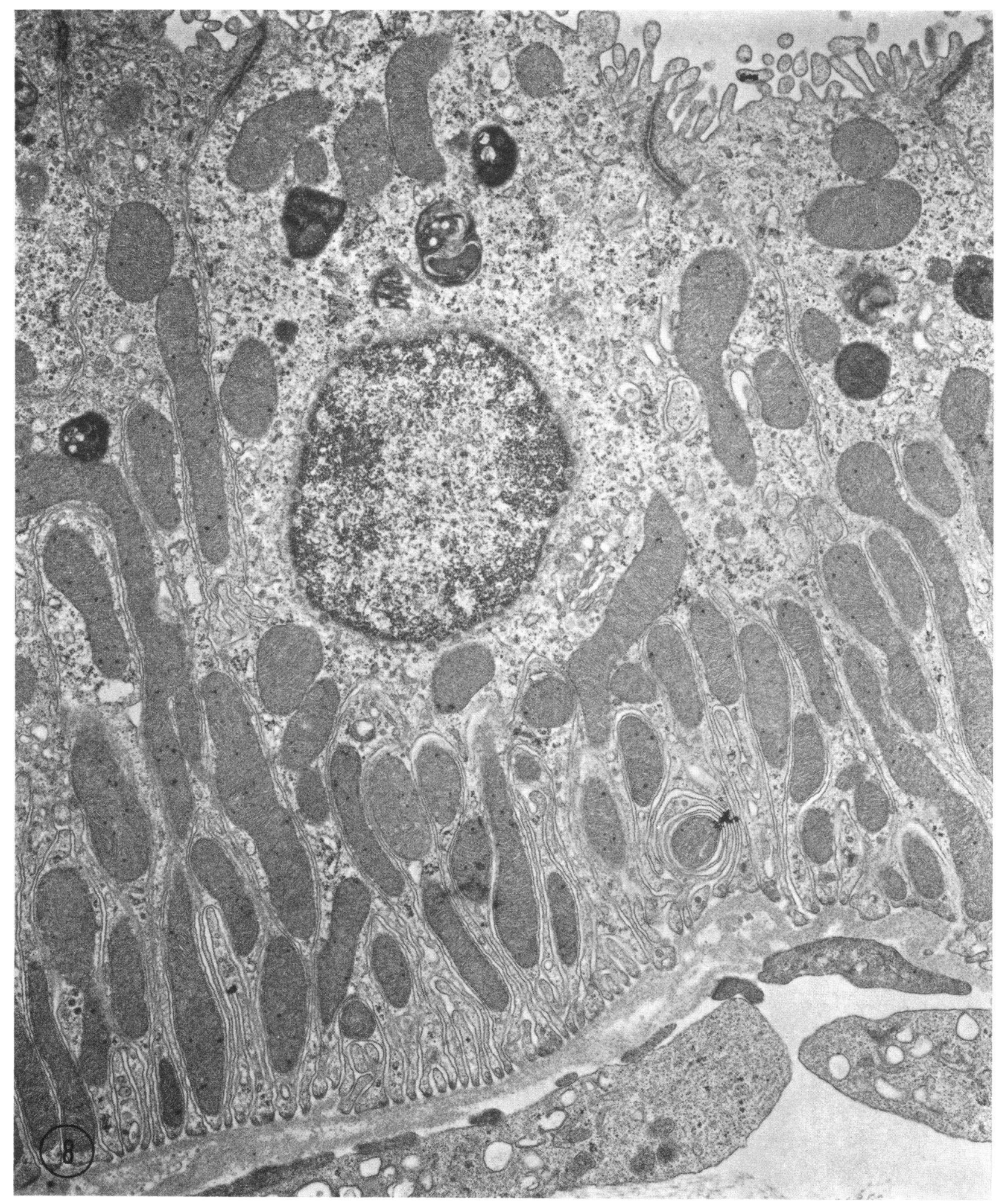

FIGURE 8 Electron micrograph of distal convoluted tubule from a DI rat converted from water diuresis to antidiuresis by the administration of exogenous vasopressin. There is no evidence of cell swelling or intercellular space enlargement. Magnification $\times 12,600$. 
TABLE II

Morphometric Measurements in Cortical Collecting Ducts of DI rats*

\begin{tabular}{|c|c|c|c|c|c|}
\hline \multirow[b]{2}{*}{ Study group } & \multicolumn{2}{|c|}{ Tubule diameter } & \multicolumn{2}{|c|}{ Cell height } & \multirow[b]{2}{*}{ Cell area } \\
\hline & Outside & Inside & Light & Dark & \\
\hline & \multicolumn{2}{|c|}{$\mu m$} & \multicolumn{2}{|c|}{$\mu m$} & $\mu m^{2}$ \\
\hline $\begin{array}{l}\text { Water diuresis } \\
\quad(n=4)\end{array}$ & $\begin{array}{c}38 \pm 5.8 \\
(n=34)\end{array}$ & $\begin{array}{l}26.1 \pm 5.1 \\
(n=35)\end{array}$ & $\begin{array}{l}5.7 \pm 1.3 \\
(n=71)\end{array}$ & $\begin{array}{l}5.3 \pm 1.11 \\
(n=61)\end{array}$ & $\begin{array}{l}601 \pm 155 \\
(n=33)\end{array}$ \\
\hline $\begin{array}{l}\text { Antidiuresis } \\
\quad(n=3)\end{array}$ & $\begin{array}{l}36.1 \pm 5.8 \\
(n=34) \\
P>0.10\end{array}$ & $\begin{array}{l}22.7 \pm 4.7 \\
(n=34) \\
P<0.01\end{array}$ & $\begin{array}{c}6.7 \pm 1.0 \\
(n=71) \\
P<0.001\end{array}$ & $\begin{array}{c}6.8 \pm 1.0 \\
(n=59) \\
P<0.001\end{array}$ & $\begin{array}{l}668 \pm 180 \\
(n=33) \\
P<0.06\end{array}$ \\
\hline
\end{tabular}

*Values represent the mean \pm the standard deviation.

distal convoluted tubules are depicted in Table III. The average height of the cells in the untreated diuretic animals was $10.5 \pm \mathrm{SD} 1.4 \mu \mathrm{m}(n=100)$ vs. $10.7 \pm \mathrm{SD} 1.6$ $\mu \mathrm{m} \quad(n=100, P>0.3)$ in vasopressin-treated rats. Measurements of the average width of the lateral intercellular spaces of the distal convoluted tubules in the two physiological conditions equalled $178 \pm \mathrm{SD} 70 \AA$ ( $n=$ $144)$ in untreated diuretic rats and $182 \pm \mathrm{SD} 82 \AA(n=$ $108)$ in vasopressin-treated animals $(P>0.5$; Table III). These morphological observations are in agreement with those obtained qualitatively and they suggest that vasopressin-induced osmotic water flow does not occur in the convoluted portion of the distal tubule.

When the surface of the kidney is viewed in vivo within the range of magnification usually employed for micropuncture $(60-100 \times)$, it is impossible to distinguish (at least on the basis of histological appearance alone) the distal convoluted tubule (early distal tubule) from the initial collecting tubule (late distal tubule); either segment is potentially accessible to renal micropuncture (Figs. $9 a$ and $b$ ). Table IV depicts the results of an analysis of 829 subcapsular tissue sections in which the cellular composition of the so-called distal tubule of the micropuncturist was assessed in three different strains of rats. Distal convoluted tubules, initial collecting tubules, and tubules representing regions of transition between these two morphologically distinct segments could all be identified just beneath the renal capsule. The cellular composition of subcapsular distal tubules was similar in Sprague-Dawley and DI rats; of the three types of tubules identified and counted, distal convoluted tubules comprised 75.2 and $77.3 \%$ of the total subcapsular tubules in the two species, respectively, while subcapsular tubules lined by collecting duct epithelium represented only 19.1 and $10.9 \%$ of the total number, respectively. However, in the Wistar rat, $48.3 \%$ of 60 subcapsular tubules were lined by epithelium characteristic of the distal convoluted tubule while $45 \%$ were lined by collecting duct epithelium. The latter findings suggest that both distal convoluted tubules and initial collecting tubules (the first portion of the cortical collecting duct before the junction) are readily accessible to micropuncture in this particular strain of Wistar rat, and that the micropuncturist may well be apt to obtain samples of distal fluid from regions of differing cell type with equal frequency. However, in both Sprague-Dawley and DI rats, there appears to be a greater likelihood of entering the distal convoluted tubule during micropuncture studies of the so-called distal tubule.

Finally, in all three strains of rats, the first junction of one renal tubule with another was always formed by tubules lined with epithelium characteristic of the collecting duct (Fig. 10). In no instance was the junction of one renal tubule with another formed by one or more distal convoluted tubules. A total of 1,628 sections were examined in 34 Sprague-Dawley rats. Nine junctions were observed and all were formed by tubules lined with collecting duct epithelium. Identical findings were noted in DI rats (2, 405 sections, 16 junctions) and Wistar rats, (944 sections, 11 junctions). Lastly, when a subcapsular tubule was identified as collecting-duct in type and followed by serial sections until it had formed a junction with another renal tubule, that segment of the tubule beyond the first junction was never observed to return to the surface before descending into the medulla.

TABLE III

Morphometric Measurements in Distal Convoluted Tubules of DI Rats*

\begin{tabular}{ccc}
\hline Study group & Cell height & $\begin{array}{c}\text { Width of lateral } \\
\text { intercellular spaces }\end{array}$ \\
\hline Water diuresis & $10.5 \pm 1.4$ & $A$ \\
$(n=4)$ & $(n=100)$ & $178 \pm 78$ \\
Antidiuresis & $10.7 \pm 1.6$ & $182 \pm 82$ \\
$(n=3)$ & $(n=100)$ & $(n=108)$ \\
& $P>0.3$ & $P>0.5$ \\
\hline
\end{tabular}

* Values represent the mean \pm the standard deviation. 

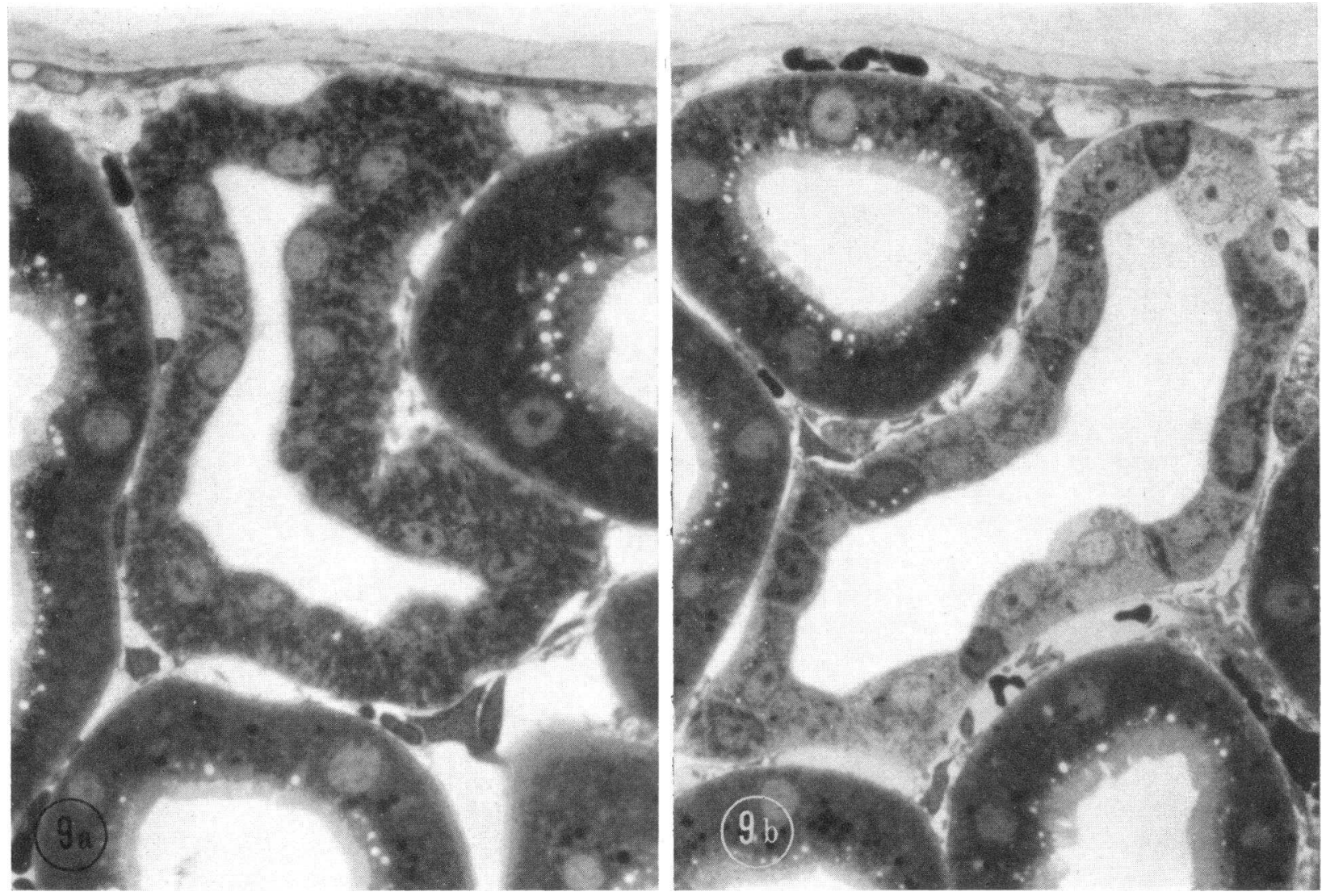

Figure 9 (a) Located just beneath the renal capsule shown at the top of this photomicrograph is a distal convoluted tubule from a Wistar rat, which is thus accessible to micropuncture. Magnification $\times 1,000$. (b) Located just beneath the renal capsule shown at the top of this photomicrograph is an initial collecting tubule from a Wistar rat, which is thus accessible to micropuncture. Magnification $\times 865$.

\section{DISCUSSION}

The present observations in DI rats provide morphological evidence (cell swelling, increased cell height, and dilatation of the lateral and basilar intercellular spaces) that the cortical segment of the collecting duct, including the initial collecting tubule, is responsive to vasopressin in vivo. These results represent the first in vivo documentation of vasopressin responsiveness by this segment of the mammalian renal tubule, although similar morphological findings have been observed in vitro in isolated perfused cortical segments of the rabbit collecting tubule. Earlier, Tisher, Bulger, and Valtin (8) described a similar morphological response to exogenous vasopressin in medullary segments of the collecting duct from DI rats. Thus, the present results, when coupled with those of earlier studies (8), provide morphological

TABLE IV

Cellular Composition of Subcapsular Distal Tubules Potentially Available for Micropuncture

\begin{tabular}{|c|c|c|c|c|}
\hline \multirow[t]{2}{*}{ Strain } & \multirow[b]{2}{*}{$\begin{array}{l}\text { No. of } \\
\text { tubules }\end{array}$} & \multicolumn{3}{|c|}{ Lined by epithelium characteristic of } \\
\hline & & $\begin{array}{c}\text { Distal } \\
\text { convoluted } \\
\text { tubule }\end{array}$ & $\begin{array}{l}\text { Collecting } \\
\text { tubule }\end{array}$ & $\begin{array}{l}\text { Transition } \\
\text { region }\end{array}$ \\
\hline Sprague-Dawley & 141 & $106(75.2 \%)$ & $27(19.1 \%)$ & $8 \quad(5.7 \%)$ \\
\hline Wistar & 60 & $29(48.3 \%)$ & $27(45 \%)$ & $4 \quad(6.7 \%)$ \\
\hline Long-Evans (Brattleboro) & 119 & $92(77.3 \%)$ & $13(10.9 \%)$ & $14(11.8 \%)$ \\
\hline
\end{tabular}




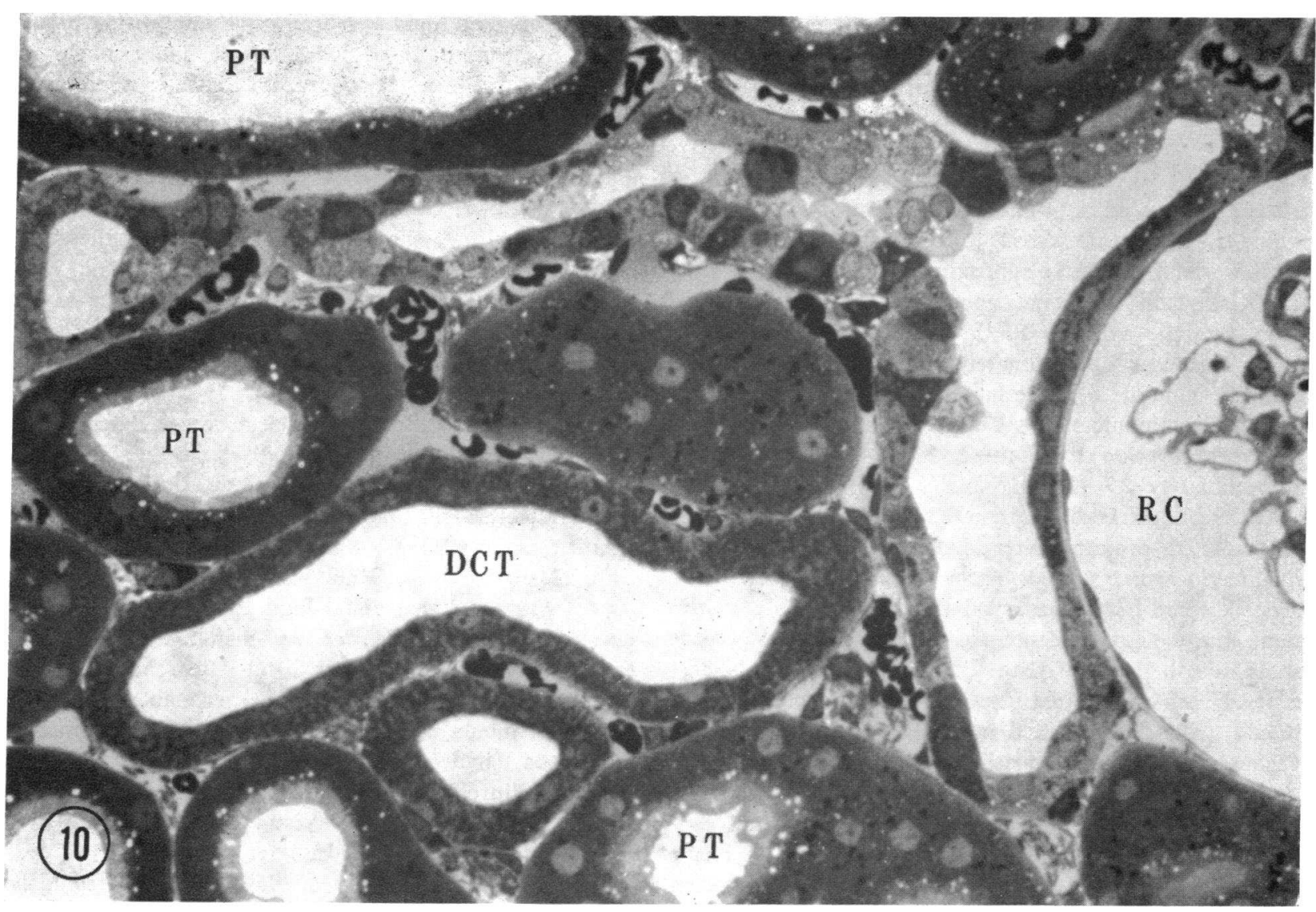

FIGURE 10 Photomicrograph of a junction at the upper right formed by two renal tubules lined by epithelium characteristic of the initial collecting tubule from a Wistar rat. PT, proximal tubule; DCT, distal convoluted tubule; RC, renal corpuscle. Magnification $\times 620$.

evidence that the entire length of the collecting duct of DI rats is responsive to vasopressin, and that vasopressin-induced osmotic water flow presumably occurs along its entire length as well.

In contrast to the implications of certain physiological studies $(5,6,17,18)$, no morphological evidence was found to suggest that the convoluted segment of the distal tubule in the rat is responsive to vasopressin. In the presence of vasopressin there was no increase in the height of the individual cells, there was no increase in the width of the lateral and basilar intercellular spaces between individual cells, and there was no change in the general appearance of the cells that might reflect the presence of increased transepithelial osmotic water flow in this segment of the nephron. It is recognized, however, that the failure to demonstrate such changes in the distal convoluted tubule does not totally exclude the possibility that some water reabsorption may occur in this segment of the nephron. In contrast to the epithelium of the collecting duct and the toad bladder, the cells of the distal convoluted tubule, like those of the proximal convoluted tubule, are highly complex in structure, possessing elaborate invaginations of the basal plasmalemma. This configuration greatly increases the cell surface-to-volume ratio and may permit greater bulk fluid flow in the absence of obvious structural changes such as cell swelling and intercellular space dilatation. Thus, possible limitations in the applicability of the morphometric techniques employed to detect transepithelial water flow must be acknowledged. In recent studies by Tisher and Kokko the same morphometric techniques were employed to relate changes in intercellular space width to varying rates of net transepithelial water flow in isolated proximal convoluted tubules exposed to various oncotic pressure gradients. Changes in net fluid reabsorption as small as $0.40-0.50 \mathrm{nl} \mathrm{mm^{-1 }}$ min $^{-1}$ were associated with significant differences in intercellular space width (19, unpublished observations). Calculations based on data derived from earlier micropuncture and microdissection studies in the rat suggest that rates of net transepithelial water reabsorption well in excess of $0.50 \mathrm{nl}$ 
$\mathrm{mm}^{-1} \mathrm{~min}^{-1}$ could be anticipated if the entire distal tubule (from the macula densa to the first junction with another renal tubule) is responsive to vasopressin. From the work of Schnermann et al. (20) it can be calculated that tubular fluid is delivered to the early distal tubule at a rate of approximately $9 \mathrm{nl} / \mathrm{min}$ in a water-loaded DI rat. The average length of the distal tubule from macula densa to the first junction with another renal tubule is approximately $2.4-2.5 \mathrm{~mm}$ (21, and Gottschalk, personal communication). In hydropenic rats the average $T F / P$ inulin ratio in the early distal tubule is approximately 5 and increases to an average value of 20 in the late distal tubule (Gottschalk, personal communication). Calculation of the rate of net fluid reabsorption from these data yields a value of

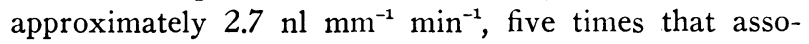
ciated with detectable intercellular space dilatation in the isolated proximal convoluted tubule. Thus, since smaller increments of transepithelial water flow have been detected in the proximal convoluted tubule by the same morphological techniques employed in the present study, we believe it quite likely that if there is significant osmotic water flow across the early distal tubule (distal convoluted tubule) in the presence of vasopressin, it should also be detectable.

The results of the present study suggest that the hypotonic tubular fluid that enters the early distal convoluted tubule from the ascending thick limb of Henle remains hypotonic to plasma throughout the distal convoluted tubule until it enters the initial collecting tubule. Thereafter, one might expect that osmotic equilibration with plasma would be achieved or approached as tubular fluid progresses further along the length of the initial collecting tubule. The present morphological demonstration of dissimilar responsiveness to vasopressin along the distal tubule of the micropuncturist also provides a possible explanation for the results of earlier micropuncture studies in Wistar rats, where the osmolality of distal tubule fluid was found to approach isotonicity at a point approximately 50$60 \%$ along the accessible length of the distal tubule (5, $6)$. As shown in Table IV, both the distal convoluted tubule (early distal tubule) and the initial collecting tubule (late distal tubule) are accessible to micropuncture in approximately equal numbers over the surface of the kidney of the Wistar rat. ${ }^{2}$ Therefore, according to the present morphological results in Wistar rats, it might be anticipated that samples of tubular fluid from the so-called early distal tubule (distal convoluted tubule) would be hypotonic to plasma, while

\footnotetext{
${ }^{2}$ Two of the seven Wistar rats in this study were obtained from the laboratory of Dr. C. W. Gottschalk. The remaining five animals were obtained from the same supplier (Hilltop Lab Animals, Scottdale, Pa. 15683.
}

samples of fluid obtained from the late distal tubule (initial collecting tubule) would be more likely to approach isotonicity. However, in contrast, micropuncture studies in either the Sprague-Dawley rat or the Brattleboro strain of the Long-Evans hooded rat would appear to be accompanied by a reduced likelihood of entering the initial collecting tubule and a greater likelihood of obtaining samples of tubular fluid from the distal convoluted tubule. Thus, in the latter two strains of rats, one might anticipate that the fluid would appear to remain hypotonic to plasma throughout the accessible length of the so-called distal tubule (as defined by the micropuncturist).

Morphological differences such as those described in the present study may help to explain the described differences between the renal micropuncture observations of Gottschalk and Mylle (5) and Lassiter, Gottschalk, and Mylle (6) and those of Lechène, Morel, Guinnebault, and de Ruffignac (22). The first two papers suggested that distal fluid approached isotonicity beyond the mid-portion of the distal tubule whereas the last paper suggested that distal fluid remained hypoosmotic to plasma throughout the accessible portion of the distal tubule under a similar array of experimental conditions (hydropenia, saline diuresis, urea diuresis, mannitol diuresis, etc.). Although the studies by both groups were performed in Wistar rats, the strains used were not identical (23). In later studies (23) it was found that more samples of fluid collected from the late distal tubule in Saclay Wistar rats (strain used by Colindres and Lechene [23]) remained hypo-osmotic than from the Wistar rats commonly used by Gottschalk and his co-workers under the same experimental conditions, and that the mean $\mathrm{TF} / \mathrm{P}$ osmolality in the second half of the distal convolution was significantly lower in the Saclay Wistar animals. It was suggested that hereditary or environmentally induced strain differences might account for the differences observed in the latter study. Based on observations in the present study, we believe it quite likely that hereditary differences in distal tubule morphology exist in these two strains of animals. We would predict that the Saclay rats resemble the Sprague-Dawley and Long-Evans strains of animals, having a greater percentage of true distal convoluted tubules among those distal tubules available for micropuncture. Of course, despite the fact that the present results do provide further insight into the random availability of distal convoluted tubules versus initial collecting tubules on the kidney surface of differing strains of rats, it must also be acknowledged that they do not establish the average percent length of the distal tubule of the micropuncturist that might be lined by the differing cell types. The demonstration of a close relationship between such a figure 
and measured osmolalities of tubular fluid at various points along the distal tubule (as defined by the micropuncturist after the dissection of latex casts) would provide further support for the thesis.

Similar morphological dissimilarities among animal species could also account for the difference in the osmolality of distal tubule fluid observed in the dog (7) and the rhesus monkey (24) as compared with the rat. Micropuncture studies in the dog have demonstrated that the tubular fluid remains hypo-osmotic throughout the accessible portion of the distal tubule, again defined as "that segment of the distal nephron between the macula densa and the point at which it joins another distal tubule to form a cortical collecting duct," (7). Combined morphological and micropuncture studies in the dog have revealed that samples of hypotonic tubular fluid are obtained from segments of the distal nephron that are morphologically characteristic of the distal convoluted tubule (C. C. Tisher and J. R. Clapp, unpublished observations).

In 1964 Ullrich, Rumrich, and Fuchs (78) reported an increase in the water permeability of the rat distal convolution during antidiuresis. By an in vivo microperfusion technique with the Stamm FW 49 strain of albino rat, the water permeability of the distal convolution during water diuresis was found to be $2.6 \times$ $10^{-8} \mathrm{~cm}^{3} / \mathrm{cm}^{2} / \mathrm{s} / \mathrm{cm} \mathrm{H}_{2} \mathrm{O}$. In the same strain of rat the water permeability during antidiuresis was $7.6 \times 10^{-8}$ $\mathrm{cm}^{3} / \mathrm{cm}^{2} / \mathrm{s} / \mathrm{cm} \mathrm{H}_{2} \mathrm{O}$. Based on our own morphological observations, it is possible that the authors were perfusing, at least in part, the initial collecting tubule, a segment that would correspond to the late distal tubule or late distal convolution. The authors' description is unclear as to just how much of the distal tubule was actually perfused, and histological identification of the perfused tubule segments was not undertaken.

The presence of functional (vasopressin responsiveness) and structural heterogeneity within the rat distal tubule (as defined at the micropuncture table) should serve to sound a note of caution to investigators attempting to establish the precise site of various physiological events in this segment of the renal tubule. It appears likely, at least in some instances, that reported functional differences between the early and late distal tubule actually reflect functional differences between the distal convoluted tubule and the initial collecting tubule. Such a circumstance should not be unexpected in view of differing embryological origins of these two morphologically distinct segments of the mammalian renal tubule. The distal convoluted tubule is derived from the metanephric blastema, whereas the collecting duct system (including the initial collecting tubule) is thought to be derived from the ureteric bud (3).
Greater future reliance should be placed on studies employing both structural and functional techniques to identify the precise site of micropuncture along the nephron. A technique has recently been described that permits the fixation of renal tubules for electron microscopy immediately after samples of fluid have been obtained via micropuncture (25); the parallel injection of latex into the lumen of the fixed tubule and the surrounding interstitium at the site of puncture facilitates precise histological identification of underlying cell types at the site of micropuncture.

The present demonstration of cellular responsiveness to vasopressin can probably be attributed to the rapid induction of antidiuresis in diuretic animals where the rate of fluid flow within the tubule presumably was high. The findings are consistent with the concept that a large volume of hypotonic fluid was entering the cortical collecting duct at a time when the luminal cell membrane was suddenly rendered more permeable to water by the action of vasopressin. The sudden increase in permeability to water permitted an initially high rate of transtubular fluid flow, which effected the appearance of cell swelling and intercellular space enlargement, at least transiently. Three lines of evidence support this view: first, the cortical collecting ducts of animals whose kidneys were fixed within 6-10 min after the establishment of antidiuresis exhibited larger and more numerous dilated intercellular spaces than did the collecting ducts of those animals whose kidneys were fixed at 30-60 min; second, enlarged intercellular spaces were observed infrequently in the cortical collecting ducts of the DI rats made severely hydropenic before the administration of vasopressin; finally, the most marked intercellular space enlargement was observed just beyond the region of transition from the distal convoluted tubule to the initial collecting tubule, i.e., that point in which the osmotic gradient between the hypotonic fluid leaving the distal convoluted tubule and the isotonic interstitial fluid surrounding the tubule should be greatest.

\section{ACKNOWLEDGMENTS}

The authors express their appreciation to Dr. Roscoe R. Robinson for many helpful discussions during the course of this investigation and for his assistance during the preparation of this manuscript. The authors also express their appreciation to Mrs. Kathy Blake, Mrs. Helen Parks, and Mrs. Betty Waller for technical assistance and to Mrs. Jessie Calder for preparation of the illustrative material.

Supported in part by grants AM 13845 and AM 10844 from the U. S. Public Health Service.

\section{REFERENCES}

1. Bloom, W., and D. W. Fawcett. 1968. The urinary system. In A Textbook of Histology. W. B. Saunders Company, Philadelphia. 9th edition. 652. 
2. Trump, B. F., and R. E. Bulger. 1968. The morphology of the kidney. In The Structural Basis of Renal Disease. E. L. Becker and J. Ellis, editors. Hoeber Medical Division of Harper \& Row, Publishers, New York. 1.

3. Huber, G. C. 1909-1910. The morphology and structure of the mammalian renal tubule. Harvey Lect. 5: 100.

4. Windhager, E. E. 1968. Microdissection of single nephrons. In Micropuncture Techniques and Nephron Function. Appleton-Century-Crofts Inc., New York. 42.

5. Gottschalk, C. W., and M. Mylle. 1959. Micropuncture study of the mammalian urinary concentrating mechanism: evidence for the countercurrent hypothesis. $\mathrm{Am}$. J. Physiol. 196: 927.

6. Lassiter, W. E., C. W. Gottschalk, and M. Mylle. 1961. Micropuncture study of net transtubular movement of water and urea in non-diuretic mammalian kidney. $\mathrm{Am}$. J. Physiol. 200 : 1139.

7. Clapp, J. R., and R. R. Robinson. 1966. Osmolality of distal tubular fluid in the dog. J. Clin. Invest. 45: 1847.

8. Tisher, C. C., R. E. Bulger, and H. Valtin. 1971. Morphology of the renal medulla in water diuresis and vasopressin-induced antidiuresis. Am. J. Physiol. 220: 87.

9. Ganote, C. E., J. J. Grantham, H. L. Moses, M. B. Burg, and J. Orloff. 1968. Ultrastructural studies of vasopressin effect on isolated perfused renal collecting tubules of the rabbit. J. Cell Biol. 36: 355 .

10. Valtin, H. 1967. Hereditary hypothalamic diabetes insipidus in rats (Brattleboro strain). A useful experimental model. Am. J. Med. 42: 814.

11. Tisher, C. C., W. J. Cirksena, A. V., Arstila, and B. F. Trump. 1969. Subcellular localization of sodium in normal and injured proximal tubules of the rat kidney. Am. J. Pathol. $57: 231$.

12. Karnovsky, M. J. 1965. A formaldehyde-glutaraldehyde fixative of high osmolality for use in electron microscopy. J. Cell Biol. 27 : 137. (Abstr.)

13. Luft, J. H. 1961. Improvements in epoxy resin embedding methods. J. Biophys. Biochem. Cytol. 9: 409.

14. Trump, B. F., E. A. Smuckler, and E. P. Benditt. 1961. A method for staining epoxy sections for light microscopy. J. Ultrastruct. Res. $5: 343$.
15. Watson, M. L. 1958. Staining of tissue sections for electron microscopy with heavy metals. J. Biophys. Biochem. Cytol. 4: 475 .

16. Reynolds, E. S. 1963. The use of lead citrate at high $\mathrm{pH}$ as an electron-opaque stain in electron microscopy. J. Cell Biol. $17: 208$.

17. Ullrich, K. J., B. Schmidt-Nielsen, R. O'Dell, G. Pehling, C. W. Gottschalk, W. E. Lassiter, and M. Mylle. 1963. Micropuncture study of composition of proximal and distal tubular fluid in rat kidney. $\mathrm{Am} . \mathrm{J}$. Physiol. 204: 527.

18. Ullrich, K. J., G. Rumrich, and G. Fuchs. 1964. Wasserpermeabilität und transtubulärer Wasserfluss corticaler Nephronabschnitte bei verschiedenen Diuresezuständen. Pfuegers Arch. Gesamte Physiol. Menschen Tiere. 280: 99 .

19. Tisher, C. C., and J. P. Kokko. 1973. Relationship between peritubular oncotic pressure gradients and morphology of the proximal tubule (PCT). Clin. Res. 21: 710. (Abstr.)

20. Schnermann, J., H. Valtin, K. Thurau, W. Nagel, M. Horster, H. Fischbach, M. Wahl, and G. Liebau. 1969. Micropuncture studies on the influence of antidiuretic hormone on tubular fluid reabsorption in rats with hereditary hypothalamic diabetes insipidus. Pfluegers Arch. Gesamte Physiol. Menschen. Tiere. 306: 103.

21. Walker, A. M., and J. Oliver. 1941. Methods for the collection of fluid from single glomeruli and tubules of the mammalian kidney. Am. J. Physiol. 134: 562.

22. Lechène, C., F. Morel, M. Guinnebault, and C. de Ruffignac. 1969. Etude par microponction de l'élaboration de l'urine. I. Chez le rat dans differents états de diurèse. Nephron. 6: 457

23. Colindres, R. W., and C. Lechene. 1972. Technical problems associated with collection of distal tubular fluid in the rat. Yale J. Biol. Med. 45: 233.

24. Bennett, C. M., B. M. Brenner, and R. W. Berliner 1968. Micropuncture study of nephron function in the rhesus monkey. J. Clin. Invest. 47:203.

25. Tisher, C. C., and J. R. Clapp. 1972. Intraluminal latex injection: An aid to the histological identification of renal tubules. Kidney Int. 2: 54 . 